\title{
Trudeau promises to boost federal health transfers when the pandemic is over
}

Cite as: CMAJ 2021 January 11;193:E61-2. doi: 10.1503/cmaj.1095912

Posted on cmajnews.com on December 10, 2020

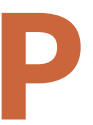

rime Minister Justin Trudeau promised after meeting with premiers in December that the federal government will increase transfer payments to the provinces for health care after the immediate crisis of the pandemic is over.

It's not the immediate increase of at least $\$ 28$ billion more in unconditional transfers each year that the premiers were seeking. However, Trudeau said the federal government will increase its share of the cost of health care in the years to come and continue to help provinces with extra costs linked to the pandemic, "whatever it takes, as long as this pandemic lasts."

That includes fully covering the cost of COVID-19 vaccines, so "the provinces and territories won't have to use their funding," and creating a federal compensation program for people who experience rare adverse reactions.

Quebec Premier François Legault said the premiers are disappointed that the federal government "refused" to discuss immediately increasing its share of health care costs from $22 \%$ to $35 \%$. Saskatchewan Premier Scott Moe said he was hopeful that the first ministers could regroup and strike a new deal in 2021.

The federal government will send nearly $\$ 42$ billion in transfer payments to the provinces and territories for health care in 2020-21. But the premiers say the federal share of health care costs hasn't kept pace with increasing expenses and falls short of the $50 \%$ the federal government agreed to cover when medicare was established.

Dr. Sacha Bhatia, director of the Institute for Health System Solutions and Virtual

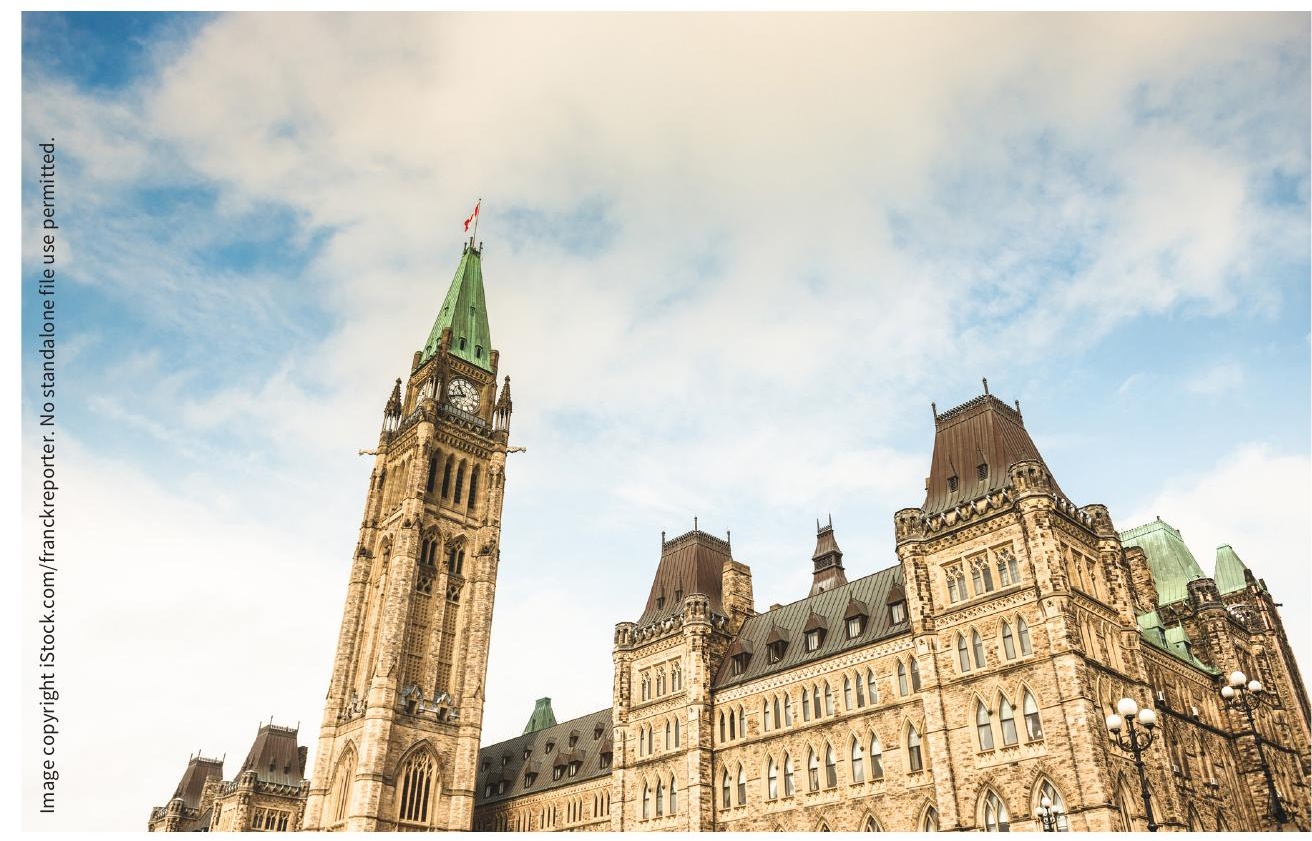

An eventual increase in federal transfers to provinces for health care will come with strings attached.

Care at Women's College Hospital in Toronto, says premiers will face pressure to increase hospital capacity in the coming months.

"Provinces might end up being in a situation where they have a real bed crunch [due to hospitalizations related to COVID-19]," Bhatia says. Provinces may need targeted federal funds to increase system capacity in the short term, "until we have a whole vaccine rollout to get to herd immunity."

Trudeau acknowledged that hospital beds are almost full and "our health care system needs fresh injections of federal funds." However, he noted that Ottawa has already sent provinces and territories an extra $\$ 25$ billion to cover costs related to COVID-19, amounting to "eight out of every 10 dollars invested in fighting this pandemic." And future increases in the federal share of health care costs will come with strings attached, including requirements around "accountability and transparency."

Trudeau did not commit to a specific timeline for hashing out a new deal with the provinces. "We need to do that in a way that is right for the coming years and decades, and right now there's a lack of certainty," he said. "We don't know what our economic situation will be in three or four months or three or four years."

Among other priorities, Canada's 13 first ministers discussed boosting resources for seniors' care. Long-term care facilities have been hardest hit by COVID19 , with outbreaks in homes across the 
country and thousands of deaths. Experts say the pandemic has exposed widespread pre-existing problems within the industry.

The Registered Nurses' Association of Ontario has called on Ontario Premier Doug Ford and Prime Minister Trudeau to push for national standards for long-term care. The RNAO's Nursing Home Basic Care Guarantee calls for improved labour standards within homes and a dedicated registered nurse for infection prevention and control.

Canada's first ministers also discussed collaborating on virtual care and moving forward on a universal pharmacare system.

In May, the federal government invested more than $\$ 240$ million in virtual care infrastructure, expanding tools and creating new platforms for mental health and primary care. Bhatia says that while this funding is for capital, provinces may need funding toward actual operations.
Many provinces have not yet signalled if they will cover virtual care beyond the pandemic.

Persisting disagreements about costsharing calculations between the federal government and provinces have created a difficult backdrop for new cooperative initiatives that involve large outlays of public funds. Trudeau alluded to pushback from some provinces on national pharmacare following the first ministers meeting, noting the federal government looks forward to "working with the premiers who are ready."

However, Bhatia says Trudeau might leverage ongoing negotiations over federal health transfers to make progress.

"The federal government could use [the example of] the COVID-19 vaccine procurement to say, 'If we had a way to nationally source and negotiate prices with pharmaceutical companies, rather than a patchwork of 13 different drug plans, maybe we could do really well,'” says Bhatia. "Certainly, you could say that the federal government's response on vaccines has been very successful. If every province was trying to negotiate with Pfizer about vaccine distribution [individually], we would be in a very different place."

Lauren Vogel, CMAJ, and Abigail Cukier, Hamilton, Ont.

Editor's note: This article combines two reports on the first ministers meeting posted on cmajnews.com.

Content licence: This is an Open Access article distributed in accordance with the terms of the Creative Commons Attribution (CC BY-NC-ND 4.0) licence, which permits use, distribution and reproduction in any medium, provided that the original publication is properly cited, the use is noncommercial (i.e., research or educational use), and no modifications or adaptations are made. See: https://creativecommons.org/ licenses/by-nc-nd/4.0/ 